\title{
Hazard Footprint-Based Normalization of Economic Losses from Tropical Cyclones in China During 1983-2015
}

\author{
Wenfang Chen ${ }^{1} \cdot$ Yi Lu$^{2} \cdot$ Shao Sun $^{3} \cdot$ Yihong Duan ${ }^{1}$ Gregor C. Leckebusch ${ }^{4}$
}

Published online: 7 June 2018

(C) The Author(s) 2018

\begin{abstract}
Loss normalization is the prerequisite for understanding the effects of socioeconomic development, vulnerability, and climate changes on the economic losses from tropical cyclones. In China, limited studies have been done on loss normalization methods of damages caused by tropical cyclones, and most of them have adopted an administrative division-based approach to define the exposure levels. In this study, a hazard footprint-based normalization method was proposed to improve the spatial resolution of affected areas and the associated exposures to influential tropical cyclones in China. The meteorological records of precipitation and near-surface wind speed were used to identify the hazard footprint of each influential tropical cyclone. Provincial-level and national-level (total) economic loss normalization (PLN and TLN) were carried out based on the respective hazard footprints, covering loss records between 1999-2015 and 1983-2015, respectively. Socioeconomic factors-inflation, population, and wealth (GDP per capita) — were used to normalize the losses. A significant increasing trend was found in inflation-adjusted losses during 1983-2015, while no significant trend was found after normalization with the TLN method. The proposed hazard footprint-based method contributes to a
\end{abstract}

Yihong Duan

duanyh@cma.gov.cn

1 State Key Laboratory of Severe Weather, Chinese Academy of Meteorological Science, 100081 Beijing, China

2 Shanghai Typhoon Institute of China Meteorological Administration, 200030 Shanghai, China

3 National Climate Center, China Meteorological Administration, 100081 Beijing, China

4 School of Geography, Earth and Environmental Sciences, University of Birmingham, Birmingham, UK more realistic estimation of the population and wealth affected by the influential tropical cyclones for the original year and the present scenario.

Keywords China - Direct economic loss · Loss normalization - Tropical cyclones - Typhoon disaster risk

\section{Introduction}

Global society has experienced a dramatic increase of losses from natural hazard-induced disasters in recent decades. Among all natural hazards, tropical cyclones (TCs) are one of the major threats to human society, and the related damages and losses are on the rise. From 1970 to 2015,5 out of 10 natural catastrophes that caused most inflation-adjusted insured losses were TCs (Swiss Re 2016).

While historical damage records can provide much information for estimating how much loss TCs will cause today, these losses need to be normalized to the current socioeconomic levels because exposure and vulnerability change over time. The procedure, commonly called loss normalization, has been applied in many studies on exploring loss trends and the effects of anthropogenic climate changes (Crompton et al. 2010; Bouwer 2011).

Most studies assume a proportional relationship between the magnitudes of losses and the exposure levels (the population and assets that are at risk) if the hazard and vulnerability remain constant (Pielke $\mathrm{Jr}$ et al. 2003; Raghavan and Rajesh 2003; Schmidt et al. 2009; Zhang et al. 2009). Using certain proxies to represent exposure levels, including population and wealth changes, the process of loss normalization can be expressed in mathematical terms as follows (adapted from Eichner 2013): 
Loss $_{\text {today }}=\operatorname{Loss}_{\text {year } X} \times \frac{\text { Proxy }_{\text {today }}}{\text { Proxy }_{\text {year } X}}$,

where Loss $_{\text {today }}$ is the normalized loss under the current socioeconomic conditions; Loss year $X$ is the original loss caused by the TC that occurred in year $X$; and Proxy $y_{\text {today }}$ and Proxy $_{\text {year } X}$ are the proxy values in the base year (usually a recent) and year $X$.

Two basic questions need to be considered in loss normalization: (1) which socioeconomic factors should be used as the proxies; and (2) what spatial resolution should be adopted for the proxies and losses. For the first, inflation, population, and wealth are three common factors to consider (Pielke Jr et al. 2008; Bouwer 2011). Among all the factors, gross domestic product (GDP) has been frequently used to represent the wealth a region or a country owns. Other indicators such as GDP per capita, income per capita, and coastal county housing units also have been used to indicate the amount of property at risk (Bouwer 2011). Population can also be a proxy for the exposure level of a region or country.

The second question is related to the difference between the area affected by the TC event and the spatial resolution of the proxies and losses. For example, when loss values are recorded for every province individually, but a TC affects only a small part of each province, the use of a national GDP or provincial GDP for loss normalization is probably unsuitable. Currently, most studies use the national or regional (such as provincial and county-level) socioeconomic indicators to normalize losses, which may lead to an over- or underestimation of the effect of exposure on the magnitudes of loss. Considering this problem, Eichner et al. (2016) proposed to use a cell-based loss normalization method to take into account the real impact area of hazards.

Most research on loss normalization focuses on the developed countries, especially the United States (Pielke Jr et al. 2008; Sander et al. 2013; Estrada et al. 2015). Only a few studies have analyzed TC impacts and losses in China based on limited loss records (Zhang et al. 2009, 2011; Fischer et al. 2015). Zhang et al. (2009) normalized the TC losses for the period of 1983-2006, using annual national GDP, and found no trend in the normalized loss data. Zhang et al. (2011) carried out a similar analysis for the period of 1984-2007, also using annual national GDP as the normalization proxy, and concluded that the increase of direct economic losses was mainly due to the socioeconomic development of China, similar to the conclusion of Zhang et al. (2009). Fischer et al. (2015) improved the loss normalization method for TCs in China by using provincial socioeconomic and loss data and longer time series of loss data (up to 2013) than previous research. These authors used both the conventional normalization method (using the consumer price index, net/disposable income, and population as proxies) and an alternative normalization method (using general income as the proxy) to normalize the loss data at the provincial level. No significant trend was found in the normalized losses using either method. The existing studies on the economic impacts of TCs in China have contributed substantially to the normalization and attribution of typhoon disaster losses. However, they were mostly carried out at the provincial and the national levels, ignoring the real footprint of each TC and regional disparities.

Based on the previous research, this study adopted a hazard footprint-based approach to normalize the direct economic losses caused by TCs in China during the period 1983-2015. The proposed method aimed to provide a more comprehensive, updated, and higher-resolution loss analysis for TC disasters in China.

\section{Data}

This study focused on the direct economic losses caused by TCs in China's mainland (including Hainan Province) from 1983 to 2015. Two kinds of official data sources of historical loss records for the TCs in China were used: (1) the total direct economic loss from each TC and the impacted provinces from 1983 to 1998, extracted from China's Tropical Cyclone Disasters Dataset (1949-1999) released by the National Climate Center (NCC) of the China Meteorology Administration (CMA) (NCC 2001); and (2) the provincial-level and mainland-wide total direct economic losses caused by each TC from 1999 to 2015, published in China's Yearbooks of Meteorology (2000-2004) (CMA 2000-2004) and China's Yearbooks of Meteorological Disaster (2005-2016) (CMA 2005-2016). Although a county-level dataset had been used by the research group in the NCC (Gemmer et al. 2011; Fischer et al. 2015; Wang et al. 2016), that dataset was compiled based on several different data sources and may have involved substantial processing due to the mismatching or incongruence among the different data sources; and the county-level dataset is not publicly available and cannot be easily accessed by the public. Thus, this study made full use of the best publicly available loss data for the impact analysis of historical TCs.

Tropical cyclone track and intensity were derived from the CMA Tropical Cyclone Best Track Dataset, including data on 6-hourly track locations, 2-min mean maximum sustained wind speed, and minimum air pressure (Ying et al. 2014). Daily precipitation data and daily maximum wind speed from 2474 nationwide meteorological observation stations were obtained from the National Meteorological Information Center (NMIC) of the CMA. 
Data on the national consumer price index (CPI), provincial GDP, provincial GDP per capita, and population during the period of 1983-2015 were all obtained from the National Bureau of Statistics of China (NBSC). ${ }^{1}$ The land area of each province was derived from the China City Statistical Yearbook (NBSC 2016).

\section{Methodology}

In this study we identified the hazard footprint of each influential TC based on the loss records and meteorological data (TC-induced wind and precipitation) and calculated the affected population and wealth based on the hazard footprint results. The loss normalization methodology proposed by Pielke Jr and Landsea (1998) and later updated by Pielke Jr et al. (2008) were adopted to conduct loss normalization at both the national and the provincial levels. The trends of normalized losses were tested using both linear regression and Mann-Kendall tests.

\subsection{Calculation of Hazard Footprint}

Hazard footprint is defined as the impact area of each influential TC, which was identified based on both the loss records and the TC-induced wind and precipitation records. Specifically, the provinces affected by each influential TC event were obtained from the historical loss records, and the actual impact area in each affected province was identified based on the TC-induced wind and rainfall intensities.

The influential TCs that caused damages (losses larger than zero) in China's mainland during 1983-2015 were selected. Then the daily maximum 10-min mean wind and daily rainfall triggered by each event were derived from the records of meteorological stations using the Objective Synoptic Analysis Technique (OSAT), which was proposed by Ren et al. (2007) for TC precipitation and modified and used by Lu et al. (2016) for TC wind.

For each influential TC event, the maximum values of the daily maximum 10-min mean wind and daily rainfall during the whole TC lifetime at each station were derived and interpolated to create raster files using the inverse distance weighting (IDW) method at a spatial resolution of $3 \mathrm{~km}$. The rainfall and wind speed raster data were respectively classified into five classes according to their intensity (Table 1) and masked using the vector file of China's boundaries. Then the two raster files of rainfall and wind for the same TC event were "mosaicked" to a new raster file of hazard class using the ArcGIS Mosaic tool, ${ }^{2}$

\footnotetext{
${ }^{1}$ http://data.stats.gov.cn/.
}

adopting the maximum of the overlapping cells as the output cell value. The hazard classes range from 1 to 5 .

The area of each hazard class in each affected province (obtained from loss records) for each influential TC event was calculated using the ArcGIS spatial analyst tool Tabulate Area. The areas in a hazard class of no less than 3that is those areas that have experienced at least heavy rain (more than $50 \mathrm{~mm}$ in $24 \mathrm{~h}$ ) or gales (more than $17.2 \mathrm{~m} \mathrm{~s}^{-1}$ )—were extracted for each affected province. These areas were taken to be the "hazard footprint" of the corresponding influential TC event. An example of a TC hazard footprint is shown in Fig. 1. All the processing of vector and raster data in this study was conducted using Python 2.7.3. ${ }^{3}$

The affected area ratio for each affected province of each TC event was calculated by dividing the area of the hazard footprint by the total land area of the province. Then the affected population (and GDP) of each province for the TC event in the original year when the disaster event happened and the base year 2015 were calculated by multiplying the affected area ratio with the total population (and GDP) of each province in the original year and 2015 (supposing the population and GDP are evenly distributed in the area of the same province because the boundaries of the county-level administrative divisions have been changing all the timethus the historical socioeconomic and loss data are most reliable and robust at the provincial level). For example, according to the results of the hazard footprint, 2006 strong tropical storm Bilis (200604) affected most of Guangxi $(81 \%)$ and Guangdong (76\%), half of Fujian $(53 \%)$ and Zhejiang (50\%), and part of Hunan (30\%) and Jiangxi (19\%). The population of the six provinces in 2006 was 46.3 (Guangxi), 94.7 (Guangdong), 35.9 (Fujian), 49.6 (Zhejiang), 65.0 (Hunan), and 45.1 (Jiangxi) million, respectively. Therefore, the total population affected by Bilis (200604) was $81 \% \times 46.3+76 \% \times 94.7+53 \% \times 35.9+50 \% \times$ $49.6+30 \% \times 65.0+19 \% \times 45.1=182.3$ million. If Bilis had occurred in 2015 , the total affected population would have been 198.4 million, supposing vulnerability remained the same.

\subsection{Loss Normalization}

This study adopted the loss normalization methodology proposed by Pielke Jr and Landsea (1998) and updated by Pielke Jr et al. (2008). Our study basically followed the "PL05" method in Pielke Jr et al. (2008), which adjusted the original economic losses for inflation, wealth, and population to a reference year-in our study, 2015 was set

\footnotetext{
$\overline{2}$ http://pro.arcgis.com/en/pro-app/tool-reference/data-management/ mosaic.htm.

3 https://www.python.org/.
} 
Table 1 Classification of tropical cyclone (TC) rainfall and wind intensity

\begin{tabular}{|c|c|c|c|c|c|}
\hline \multirow[t]{2}{*}{ Class } & \multicolumn{2}{|l|}{ 24-Hour rainfall } & \multicolumn{3}{|l|}{ Wind } \\
\hline & Grade & $\begin{array}{l}\text { Range } \\
(\mathrm{mm})\end{array}$ & Grade & Beaufort scale & $\begin{array}{l}\text { Range } \\
\left(\mathrm{m} \mathrm{s}^{-1}\right)\end{array}$ \\
\hline 1 & Under moderate rain & $0-25.00$ & Strong breeze & 6 & $10.80-13.90$ \\
\hline 2 & Big rain & $25.01-50.00$ & High wind & 7 & $13.91-17.20$ \\
\hline 3 & Heavy rain & $50.01-100.00$ & Gale & 8 & $17.21-20.80$ \\
\hline 4 & Very heavy rain & $100.01-250.00$ & Strong gale & 9 & $20.81-24.50$ \\
\hline 5 & Extreme heavy rain & $250.01-1000$ & Storm & 10 & $24.51-200$ \\
\hline
\end{tabular}

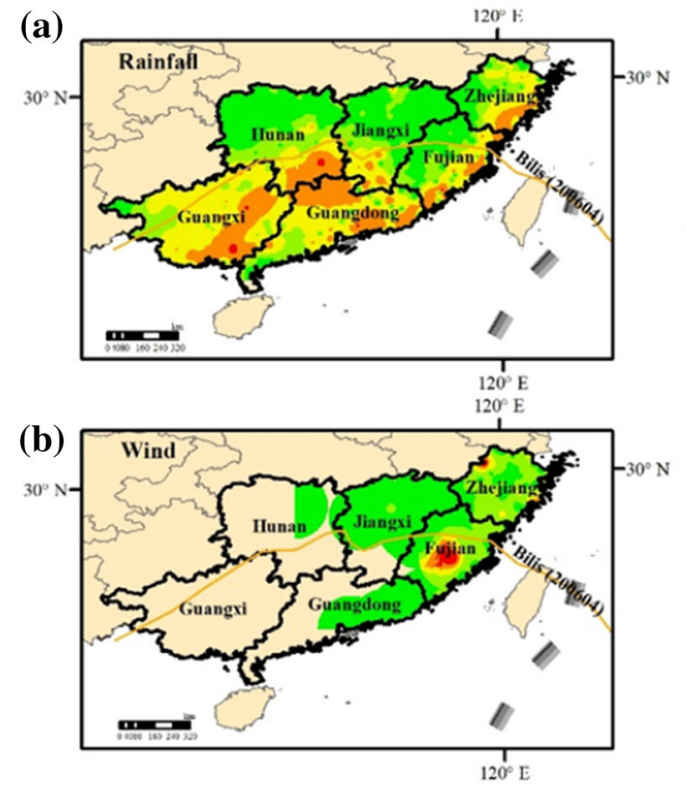

Fig. 1 Example of a tropical cyclone (TC) hazard footprint in China's mainland: spatial distributions of (a) rainfall class; (b) wind class; and (c) hazard footprint of 2006 tropical cyclone Bilis (200604). Since 1959, each TC that develops over the western North Pacific (to the north of the equator and to the west of $180^{\circ} \mathrm{E}$, and includes the South China Sea) with maximum sustained wind speed

as the reference year. The method can be expressed using the following equation:

$$
\text { NLoss } 2015=\text { Loss }_{\text {original }} \times R \_ \text {Inf } \times R \_ \text {Wealth } \times R \_ \text {Pop }
$$

NLoss $_{2015}$ is the normalized loss, Loss $_{\text {original }}$ is the original loss record. The inflation ratio $\left(R \_I n f\right)$ was calculated by dividing the national CPI of 2015 by the national CPI of the year when the TC event happened. The inflation-adjusted losses were calculated by multiplying Loss $_{\text {original }}$ with only $R \_I n f$, and were used to replace the original losses for investigation before adjusting for exposures.

The GDP per capita was used in this study to represent the wealth of a region or country. Thus, the wealth ratio $\left(R_{-}\right.$Wealth) was derived by dividing the GDP per capita in

\section{(c) Hazard footprint}

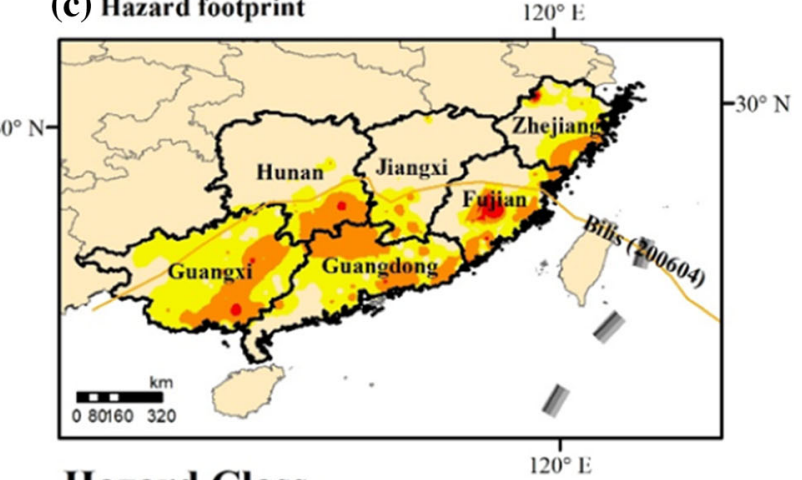

Hazard Class

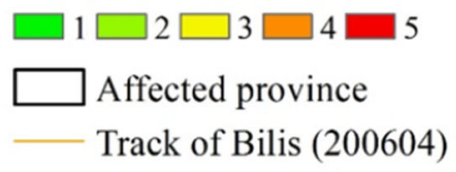

over $24.4 \mathrm{~m} \mathrm{~s}^{-1}$ (tropical storms) has been assigned an international number for identification. It originally consists of 4 digits with the former two digits denoting the year, and the latter two denoting the number of the TCs with intensities above tropical storm. Here we added two more digits with the first four representing the year of event for better clarity

2015 by the inflation-adjusted GDP per capita in the occurrence year of the TC event. The inflation-adjusted GDP per capita was derived by multiplying the original GDP per capita by the inflation ratio.

The population ratio $\left(R \_P o p\right)$ was derived by dividing the affected population if the event had happened in 2015 by the affected population derived using the hazard footprint as described in Sect. 3.1.

To make full use of the collected data, loss normalization was conducted in two parts: one was the provinciallevel loss normalization for TCs in 1999-2015, and the other was the national-level (total) loss normalization for TCs in 1983-2015. 
(1) Provincial-level loss normalization (PLN) for TCs in 1999-2015. The normalized loss for each TC was calculated as follows:

$$
\begin{aligned}
P L N \_ \text {Loss }_{i \_2015}= & \sum_{j=1}^{m} \operatorname{Loss}_{i j} \times R \_ \text {Inf } i \times R \_ \text {Wealth } \\
& \times R \_ \text {Pop } \\
&
\end{aligned}
$$

where PLN_Loss ${ }_{i}$ 2015 is the normalized total loss of the TC event $i$ supposing it happened in 2015; $\operatorname{Loss}_{i j}$ is the original loss in province $j$ caused by the event $i ; R_{-} \operatorname{Inf}_{i}$ is the inflation ratio for the year of the TC event's occurrence; $R_{-}$Wealth $_{i j}$ is the wealth ratio for province $j$ and event $i$; and $R \_P o p_{i j}$ is the population ratio for province $j$ and event $i$.

Since $R \_$Inf $f_{i} \times R \_$Wealth $h_{i j}$ in the above equation cancels out $R_{-} \operatorname{Inf} f_{i}$, the equation can be rewritten as:

$P L N \_$Loss $_{i \_2015}=\sum_{j=1}^{m} \operatorname{Loss}_{i j} \times\left(\frac{G D P p c_{2015 j}}{G D P p c_{i j}}\right) \times R \_P o p_{i j}$

where $G D P p c_{2015 j}$ and $G D P p c_{i j}$ are the GDP per capita of province $j$ in 2015 and in the year when event $i$ happened, respectively.

(2) National-level (total) loss normalization (TLN) for TCs in 1983-2015. The normalized loss (TLN_Loss $\left.{ }_{i \_2015}\right)$ for each TC was calculated as follows:

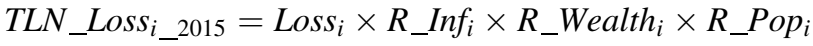

in which $\operatorname{Loss}_{i}$ is the original total loss, and for the affected region of the event $i, R_{-} W_{e a l t h}$ and $R_{-}$Pop $_{i}$ were related in the calculation. The equation can be rewritten as:

$T L N \_L o s s_{i \_2015}=$ Loss $_{i} \times A f f e c \_G D P_{2015 j} / A f f e c \_G D P_{i j}$

where Affec_GDP $2015 j$ and $A f f e c_{-} G D P_{i j}$ are the total affected GDP in the affected area in 2015 supposing the event $i$ happened, and in the original year, respectively (the calculation method has been explained in Sect. 3.1).

\subsection{Trend Analysis}

To understand the changes in TC losses, the trends in frequency and loss time series were analyzed using statistical methods. Two typical methods were applied in this study: the least square linear regression and the MannKendall tests. The former is a parametric test and assumes there is a linear trend in the time series (Haan 1977; Pattanayak and Kumar 2013); the latter is a non-parametric test that has been widely used to detect trends in environmental time series (Mann 1945; Kendall 1975). For both methods, significances have been tested at the level of 0.05 .

\section{Results}

The characteristics of the 217 influential TCs during 1983-2015 were summarized and analyzed first, and then both the provincial and the national level normalized loss results were presented. The high-risk provinces and top influential TC events with highest normalized losses were identified thereafter. Trend in normalized losses was tested, and no trend was found in the normalized losses.

\subsection{Characteristics of Influential Tropical Cyclones During 1983-2015}

According to the CMA, the intensity of TCs can be classified into six classes based on the maximum wind speeds at landfall or at the closest point to the mainland coastline: Tropical depression (TD, 10.8-17.1 $\mathrm{m} \mathrm{s}^{-1}$ ); Tropical storm (TS, 17.2-24.4 $\mathrm{m} \mathrm{s}^{-1}$ ); Strong tropical storm (STS, 24.5-32.6 $\mathrm{m} \mathrm{s}^{-1}$ ); Typhoon (TY, 32.7-41.4 $\mathrm{m} \mathrm{s}^{-1}$ ); Strong typhoon (STY, 41.5-50.9 $\mathrm{m} \mathrm{s}^{-1}$ ); and Super typhoon, ( $\left.\geq 51.0 \mathrm{~m} \mathrm{~s}^{-1}\right)$.

During 1983-2015, a total of 217 events caused losses (larger than 0). In the loss dataset, two successive events, including 2012 tropical cyclones Saola (201209) and Damrey (201210), and 2012 tropical cyclones Tembin (201214) and Bolaven (201215), were grouped as one event with one total loss value because their losses could not be easily separated. The intensity of such an event group was defined as the maximum intensity of the two composing TCs. Among the 217 influential TCs, 195 (89.9\%) made landfall on China's mainland, and only a few passed by off the coast of China and dissipated over open water.

Among all the influential TC events in the 1983-2015 period, STSs had the highest frequency ratio, and TYs had the highest ratio in terms of inflation-adjusted total loss, followed by STSs and STYs (Fig. 2). While the frequency ratio of SuperTYs (1\%) was much lower than that of TSs (20\%), SuperTYs caused total losses that were almost as high as those of the TSs (with a ratio of 7\%). This indicates the great damage potentials triggered by SuperTYs.

Figure 3 shows the temporal changes of the frequency of influential TCs ranging from 1 (in 1983) to 13 (in 2013), with an annual average of 6.7. The average annual frequency during 1983-1999 was 5.7, versus 7.5 during 2000-2015. The linear fit and test of significance indicate that there is a significant upward trend ( $p$ value $=0.01$, significant at 0.05 level) in the frequency, although the linear regression model does not fit very well considering a low value of $R^{2}(0.2$, that is only $20 \%$ of total variance in frequency can be explained by the model). 


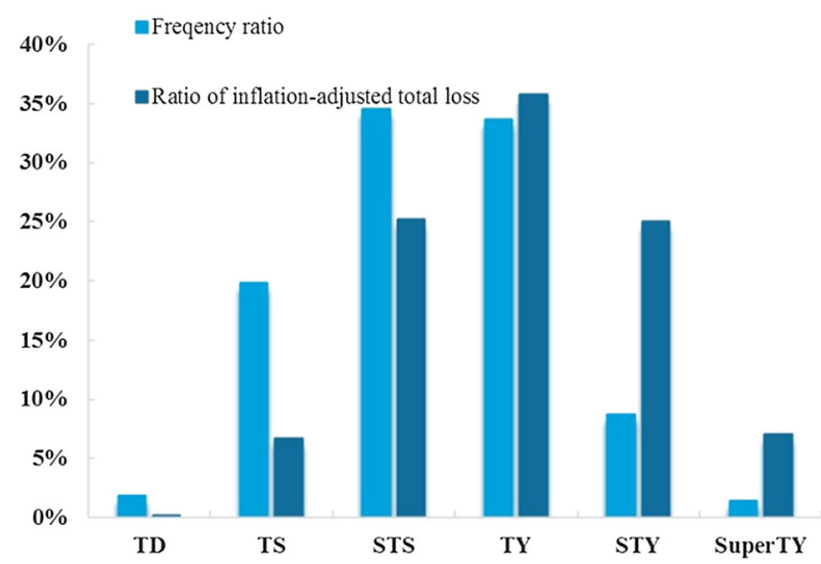

Fig. 2 Frequency ratios and inflation-adjusted total loss ratios, grouped by intensity classes, of the 217 influential tropical cyclones that affected China's mainland during 1983-2015 (TD tropical depression, $T S$ tropical storm, STS strong tropical storm, $T Y$ typhoon, STY strong typhoon, SuperTY super typhoon)
Table 2 shows the top 10 influential TCs by inflationadjusted total loss (in billion CNY), and Fig. 4 shows their tracks. All 10 TCs made landfall on China's mainland. Most of the top 10 influential TCs made direct landfall in Zhejiang and Fujian Provinces, with landfall intensities no less than $25 \mathrm{~m} \mathrm{~s}^{-1}$ (STS).

\subsection{Provincial-Level Loss Normalization (PLN) Results}

According to the provincial TC loss records, 20 provinces were affected during $1999-2015$ by the 126 influential TC events. The provinces of Zhejiang, Fujian, Guangdong, and Guangxi were affected most frequently by TCs, more than 40 times each in the 17 years (Table 3 and Fig. 5). The top five provinces with the highest inflation-adjusted losses and normalized losses were Zhejiang, Guangdong, Fujian, Guangxi, and Hainan. The ranks of the original losses,
Fig. 3 Scatter plot showing the frequency of the 217 influential tropical cyclones in China during 1983-2015 and the linear fit (the dotted line)

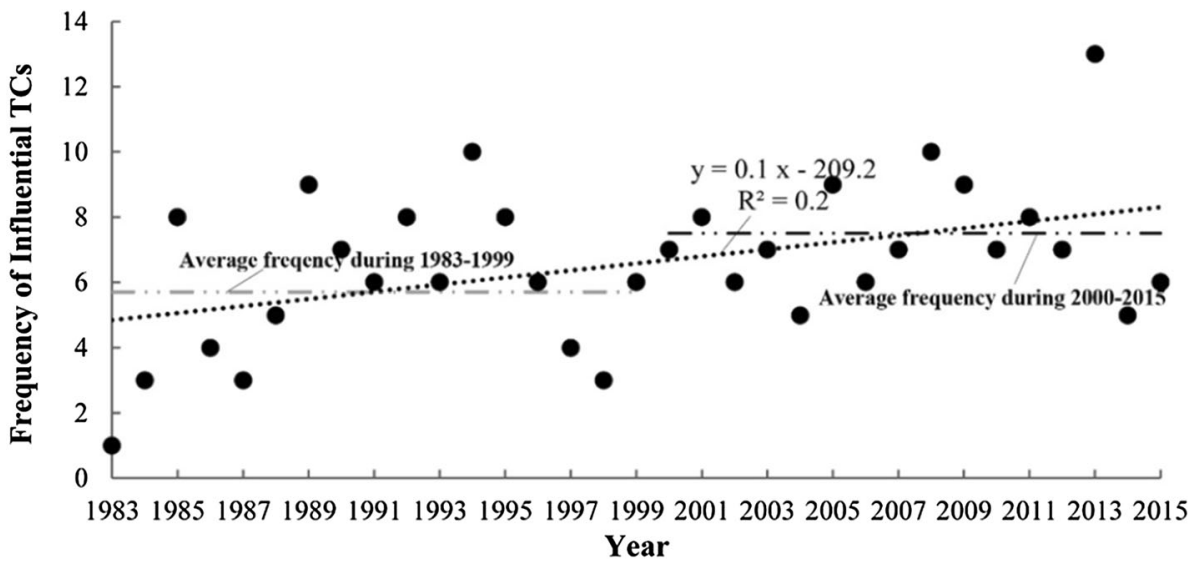

Table 2 Top 10 influential tropical cyclones in China, 1983-2015, by inflation-adjusted total loss (in 2015 billion CNY and USD)

\begin{tabular}{|c|c|c|c|c|c|c|c|}
\hline No. & Typhoon ID & Year & Typhoon name & Landfall (yes/no) & $\begin{array}{l}\text { Maximum wind } \\
\operatorname{speed}^{\mathrm{a}}\left(\mathrm{m} \mathrm{s}^{-1}\right)\end{array}$ & $\begin{array}{l}\text { Intensity } \\
\text { class }\end{array}$ & $\begin{array}{l}\text { Inflation-adjusted total losses } \\
\text { (in } 2015 \text { bn CNY (USD)) }\end{array}$ \\
\hline 1 & 199608 & 1996 & Herb & Yes & 35 & TY & $93.42(15.00)$ \\
\hline 2 & 201323 & 2013 & Fitow & Yes & 42 & STY & $65.30(10.48)$ \\
\hline 3 & 199711 & 1997 & Winnie & Yes & 40 & TY & $60.75(9.75)$ \\
\hline 4 & 201209,201210 & 2012 & Saola, Damrey & Yes & 25 & STS & $54.28(8.71)$ \\
\hline 5 & 200604 & 2006 & Bilis & Yes & 30 & STS & $45.50(7.31)$ \\
\hline 6 & 201409 & 2014 & Rammasun & Yes & 70 & SuperTY & $45.28(7.27)$ \\
\hline 7 & 201211 & 2012 & Haikui & Yes & 42 & STY & $39.89(6.40)$ \\
\hline 8 & 199406 & 1994 & Tim & Yes & 30 & STS & $37.68(6.05)$ \\
\hline 9 & 199417 & 1994 & Fred & Yes & 40 & TY & $32.41(5.20)$ \\
\hline 10 & 199615 & 1996 & Sally & Yes & 50 & STY & $31.29(5.02)$ \\
\hline
\end{tabular}

$1 \mathrm{USD}=6.2284 \mathrm{CNY}$, which was the average exchange rate in 2015 reported by NBSC (2015)

STS strong tropical storm, TY typhoon, STY strong typhoon, SuperTY super typhoon

${ }^{a}$ At landfall or at the closest point to the coast 


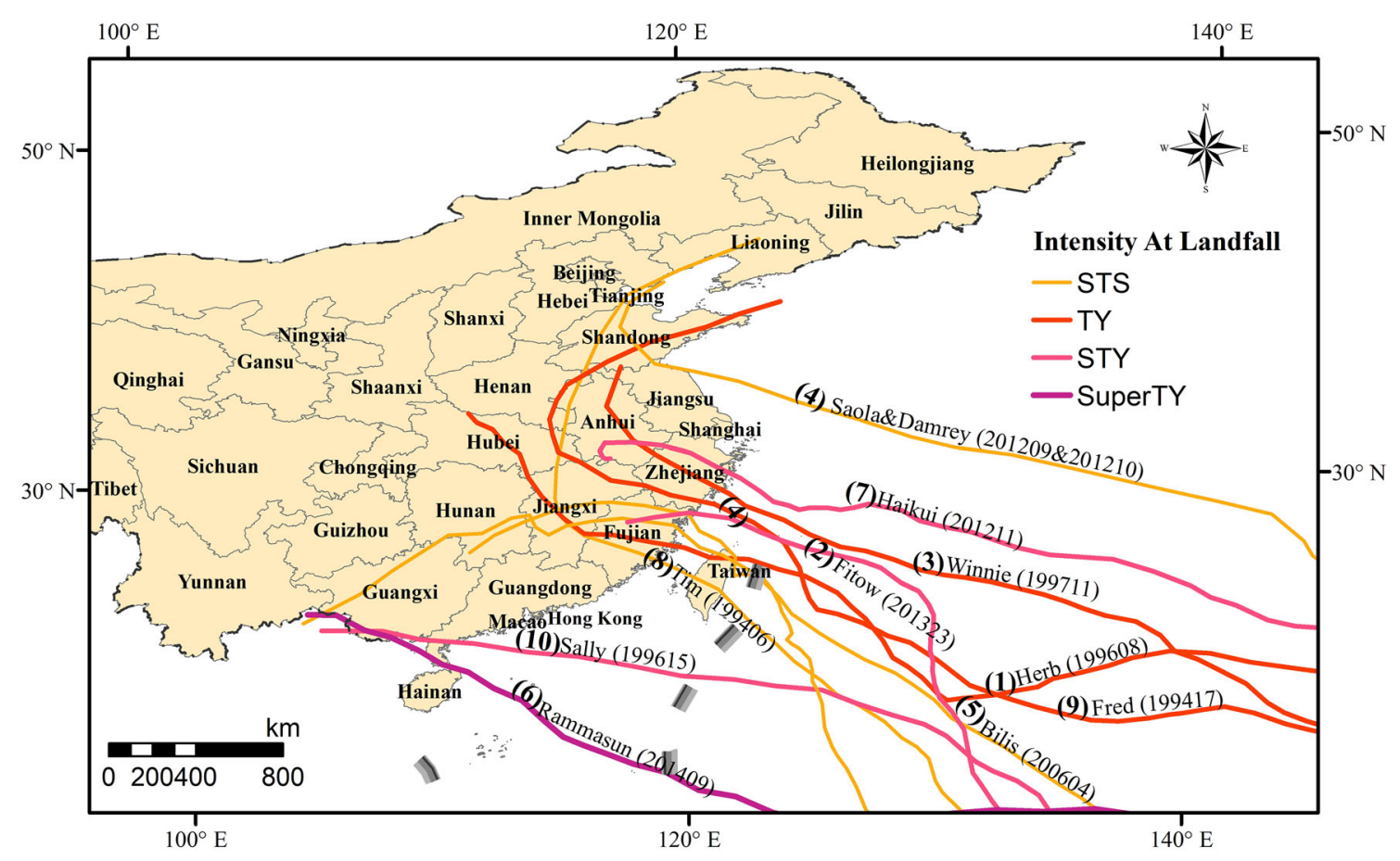

Fig. 4 Tracks and landfall intensities of the top 10 influential (by inflation-adjusted total loss) tropical cyclones in China's mainland, 1983-2015 (STS strong tropical storm, TY typhoon, STY strong typhoon, SuperTY super typhoon)

Table 3 Losses and frequencies of the 126 influential tropical cyclones in the 20 affected provinces in China during 1999-2015 (the rankings are indicated in parentheses)

\begin{tabular}{|c|c|c|c|c|}
\hline Province & $\begin{array}{l}\text { Original losses } \\
\text { (in bn CNY) }\end{array}$ & $\begin{array}{l}\text { Inflation-adjusted losses } \\
\text { (in } 2015 \text { bn CNY) }\end{array}$ & $\begin{array}{l}\text { Normalized losses } \\
\text { (in } 2015 \text { bn CNY) }\end{array}$ & Frequency of influential TCs \\
\hline Zhejiang & $221.5(1)$ & $259.5(1)$ & $504.6(1)$ & $62(1)$ \\
\hline Fujian & $98.9(3)$ & $124.6(3)$ & $372.2(2)$ & $49(2)$ \\
\hline Guangdong & $184.7(2)$ & $209.1(2)$ & $369.2(3)$ & $45(3)$ \\
\hline Guangxi & $61.4(4)$ & $73.1(4)$ & $210.2(4)$ & $43(4)$ \\
\hline Hainan & $52.5(5)$ & $60.6(5)$ & $129.9(5)$ & $38(5)$ \\
\hline Hunan & $28.8(6)$ & $37.0(6)$ & $117.0(6)$ & $25(6)$ \\
\hline Shandong & $23.6(7)$ & $27.0(7)$ & $54.3(7)$ & $19(7)$ \\
\hline Anhui & $18.0(9)$ & $21.0(9)$ & $43.9(8)$ & $15(8)$ \\
\hline Jiangsu & $15.0(10)$ & $17.9(10)$ & $41.0(9)$ & $12(9)$ \\
\hline Jiangxi & $13.7(12)$ & $16.2(11)$ & $35.9(10)$ & $12(10)$ \\
\hline Liaoning & $21.5(8)$ & $23.0(8)$ & $26.4(11)$ & $11(11)$ \\
\hline Hebei & $14.6(11)$ & $15.5(12)$ & $16.6(12)$ & $8(12)$ \\
\hline Hubei & $5.5(13)$ & $6.2(13)$ & $11.8(13)$ & $8(13)$ \\
\hline Yunnan & $5.4(14)$ & $5.8(14)$ & $9.2(14)$ & $6(14)$ \\
\hline Shanghai & 3.7 (15) & $4.5(15)$ & 7.7 (15) & $4(15)$ \\
\hline Henan & $1.3(17)$ & 1.7 (17) & $4.5(16)$ & $2(16)$ \\
\hline Jilin & 1.9 (16) & $2.0(16)$ & $3.3(17)$ & $2(17)$ \\
\hline Heilongjiang & $1.1(18)$ & $1.2(18)$ & $1.2(18)$ & $2(18)$ \\
\hline Tianjin & 0.2 (19) & 0.3 (19) & 0.9 (19) & $1(19)$ \\
\hline Guizhou & $0.2(20)$ & $0.2(20)$ & $0.5(20)$ & $1(20)$ \\
\hline
\end{tabular}




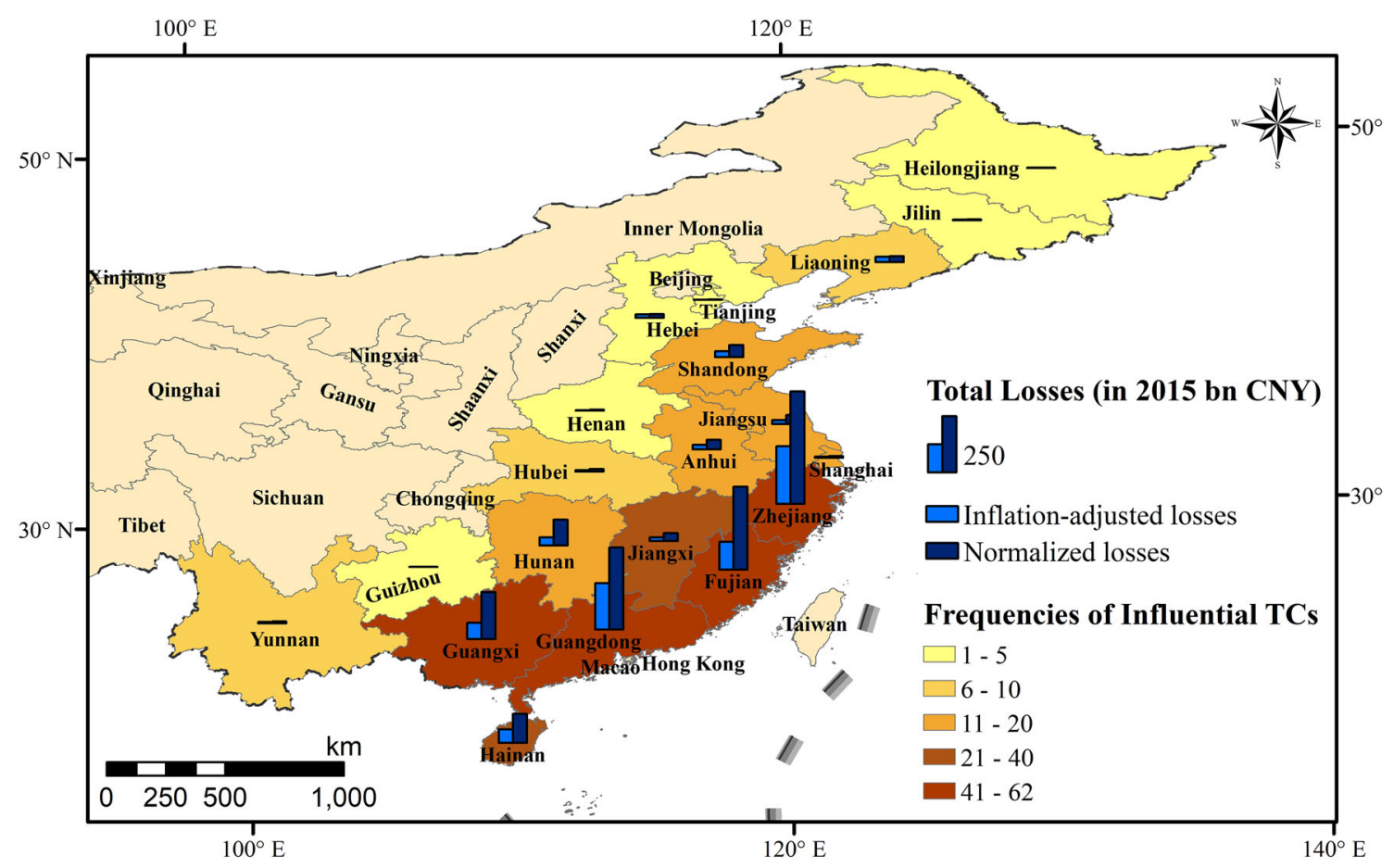

Fig. 5 Spatial distribution of the frequencies and total losses from the 126 influential tropical cyclones in the 20 affected provinces in China's mainland during 1999-2015

inflation-adjusted losses, and normalized losses in the affected provinces are almost consistent with the rank of frequency of influential TCs (the correlation coefficients are larger than 0.8 ). This indicates that the spatial distribution of provincial losses is mainly influenced by the frequency of influential TCs.

Figure 6 shows the temporal development of inflationadjusted losses and normalized losses. The linear fits show that there are no statistically significant trends in either inflation-adjusted losses or normalized losses ( $p$ values are 0.08 and 0.14 , respectively). The result of the MannKendall trend test also indicates no significant trend (tested at the significance level of 0.05 , with $p$ values of 0.15 and 0.09 , respectively).

\subsection{National-Level (Total) Loss Normalization (TLN) for Tropical Cyclones in 1983-2015}

The statistics of the normalization factors for the 217 influential TCs are given in Table 4. Among the three ratios, $R_{-}$Wealth has the largest range and standard deviation, followed by $R \_$Inf and $R \_P o p$.

The annual inflation-adjusted losses and normalized losses during 1983-2015 and their trends are shown in Fig. 7. The largest inflation-adjusted loss and normalized loss both occurred in 1996 (141.9 and 876.8 billion CNY in 2015 prices). For inflation-adjusted losses, the $p$ value of the linear fit is $0.01(<0.05)$, indicating a significant

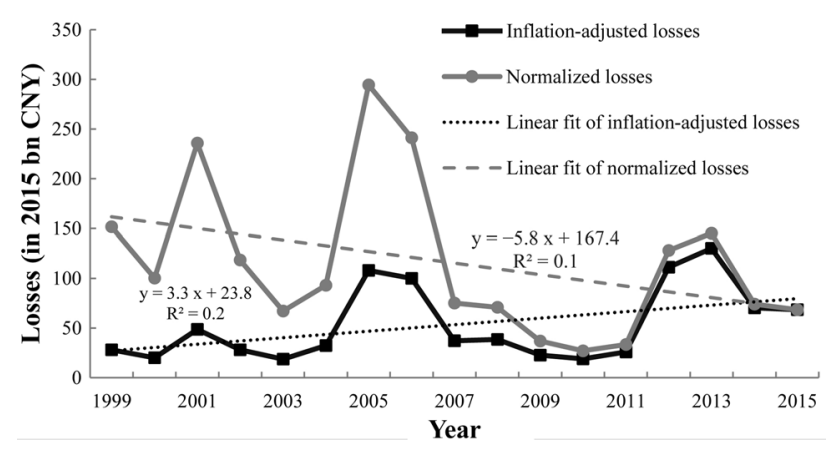

Fig. 6 Inflation-adjusted losses and normalized losses (provinciallevel loss normalization, PLN) from the 126 influential tropical cyclones in China during 1999-2015 and their linear fits

Table 4 Statistical characteristics of the three normalization factors_-inflation ratio $\left(R \_I n f\right)$, wealth ratio $\left(R_{-} \_\right.$Wealth $)$, and population ratio $\left(R \_\right.$Pop $)$for the 217 influential tropical cyclones

\begin{tabular}{llcl}
\hline & $R \_$Inf & $R_{-}$Wealth & $R_{-}$Pop \\
\hline Min. & 1.0 & 1.0 & 1.0 \\
Max. & 5.3 & 13.7 & 2.0 \\
Mean & 1.9 & 3.8 & 1.2 \\
SD & 1.1 & 2.8 & 0.2 \\
\hline
\end{tabular}

upward trend with a slope of 3.3. For normalized losses, the linear fits show that there are no statistically significant trends because the $p$ value is 0.18 ( $>0.05)$. The Mann- 
Fig. 7 Total annual inflationadjusted losses and normalized losses (national-level loss normalization, TLN) from the 217 influential tropical cyclones in China during 1983-2015 and their linear fits

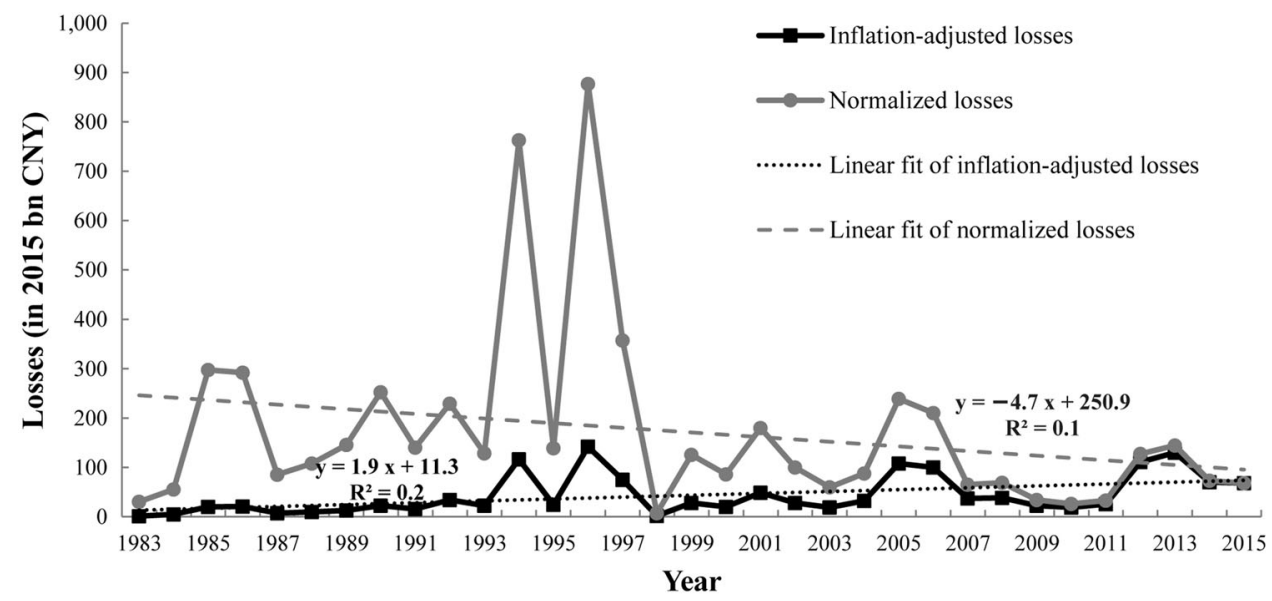

Table 5 Top 10 influential tropical cyclones in China by normalized losses by the national-level (total) loss normalization (TLN) method during 1983-2015

\begin{tabular}{lllllllll}
\hline No. & Year & Typhoon ID & Name & $\begin{array}{l}\text { Original loss } \\
\text { (in bn CNY) }\end{array}$ & $R_{-}$Inf & $R_{-}$Wealth & $R_{-}$Pop & $\begin{array}{l}\text { Normalized loss (in 2015 } \\
\text { bn CNY (USD)) }\end{array}$ \\
\hline 1 & 1996 & 199608 & Herb & 65.3 & 1.4 & 6.0 & 1.1 & $611.8(98.23)$ \\
2 & 1997 & 199711 & Winnie & 43.6 & 1.4 & 4.0 & 1.2 & $283.9(45.58)$ \\
3 & 1994 & 199406 & Tim & 20.8 & 1.8 & 5.8 & 1.2 & $254.8(40.91)$ \\
4 & 1994 & 199417 & Fred & 17.9 & 1.8 & 5.5 & 1.3 & $226.1(36.30)$ \\
5 & 1996 & 199615 & Sally & 21.9 & 1.4 & 4.2 & 1.3 & $172.3(27.66)$ \\
6 & 1992 & 199216 & Polly & 7.6 & 2.6 & 5.7 & 1.2 & $136.7(21.95)$ \\
7 & 1986 & 198607 & Peggy & 2.1 & 4.4 & 7.8 & 1.8 & $130.4(20.94)$ \\
8 & 2006 & 200604 & Bilis & 34.8 & 1.3 & 2.0 & 1.1 & $97.6(15.67)$ \\
9 & 1994 & 199405 & Nameless & 8.5 & 1.8 & 4.4 & 1.4 & $93.2(14.96)$ \\
10 & 1985 & 198506 & Jeff & 1.2 & 4.7 & 11.3 & 1.3 & $88.4(14.19)$ \\
\hline
\end{tabular}

Kendall trend test for the annual inflation-adjusted losses also shows a significant upward trend ( $p$ value $=0.0004)$, while the annual normalized losses show no significant trend at the significant level of 0.05 because the $p$ value is -0.06 ( \pm of the $p$ value denotes upward/downward trend).

The major information for the top 10 influential TCs by normalized losses is shown in Table 5, and their tracks are shown in Fig. 8. The 10 TCs mostly made landfall in the three coastal provinces: Zhejiang, Fujian, and Guangdong. The largest normalized loss was caused by 1996 typhoon Herb (199608), which made landfall in Fujian Province with the maximum wind speed of $35 \mathrm{~m} \mathrm{~s}^{-1}$ (TY in intensity class). Table 5 shows that for most of the top 10 influential TCs, the major factor contributing to the normalized losses is $R_{-}$Wealth, which indicates that the areas affected by those TCs had experienced substantial growth in GDP per capita by 2015, compared to the 1990s.

To compare the two normalization methods, the normalized results for the influential TCs during 1999-2015 are shown in the scatter plot (Fig. 9). The linear fit shows that the two sets of normalized losses are highly correlated with a $R^{2}$ equal to 0.98 . The differences between PLNlosses and TLN-losses for the 126 influential TCs are mostly slight, ranging from -1.03 to 33.81 , with an average of 1.83 (in 2015 bn CNY) during 1999-2015. Therefore, the results of the hazard footprint-based loss normalizations at both the provincial and national levels have shown great consistency. The results of provincial distribution of the PLN-losses during 1999-2015 provide credible and important information for identifying highrisk areas although the loss data only cover a period of 17 years.

The conventional loss normalization method, which takes account of the whole area of the affected provinces instead of the cell-based hazard footprints, was also applied to the 217 influential TCs during 1983-2015. Figure 10 shows that the hazard footprint-based and non-hazard footprint-based normalized losses are highly correlated, with a coefficient of 0.77 and a $p$ value lower than 0.05 


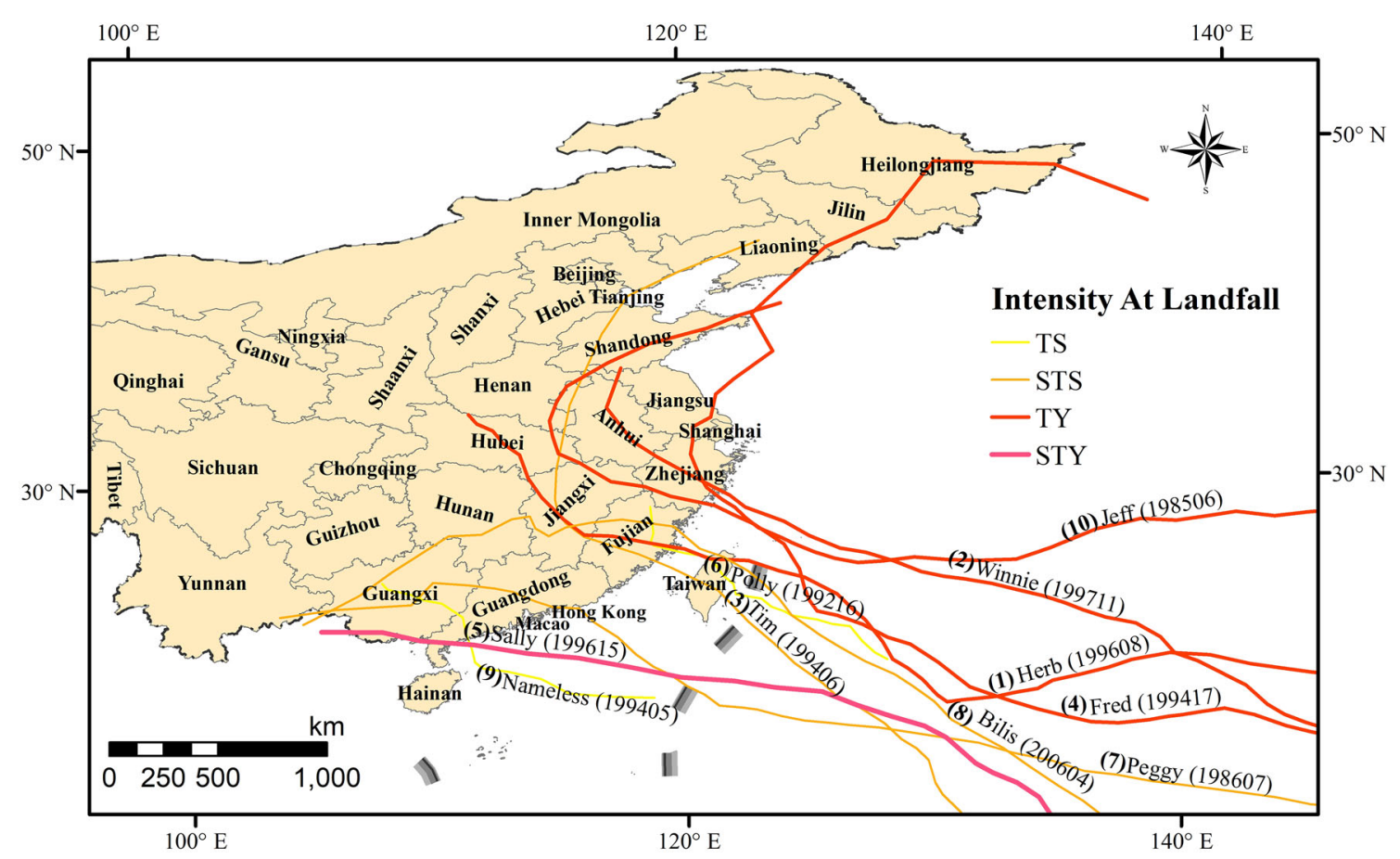

Fig. 8 Tracks and landfall intensities of the top 10 influential TCs (by normalized total losses) in China's mainland during 1983-2015 (TS tropical storm, STS strong tropical storm, TY typhoon, STY strong typhoon)

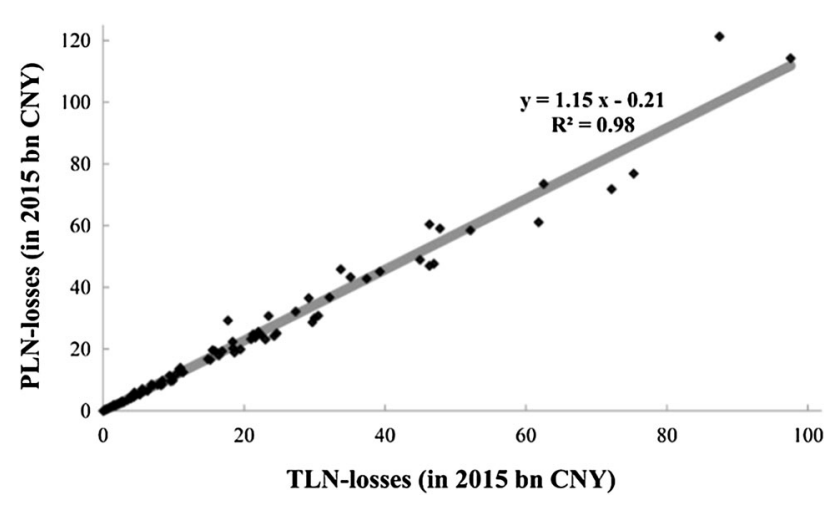

Fig. 9 Scatter plot showing the correlation between the loss normalization results from the provincial-level loss normalization (PLN) and the national-level (total) loss normalization (TLN) methods for the 126 influential tropical cyclones in China's mainland during 1999-2015

(indicating the linear relationship is significant at 0.05 level). The total annual normalized losses based on the non-hazard footprint normalization method are about $30 \%$ higher on average than the results based on the hazard footprint-based TLN method. The largest difference appears in 1994, with a value of 257.7 billion CNY (Fig. 11). In that year, the major contributing influential TC events were typhoon Tim (199406) and Fred (199417), with differences of 73.5 and 69.6 billion CNY respectively

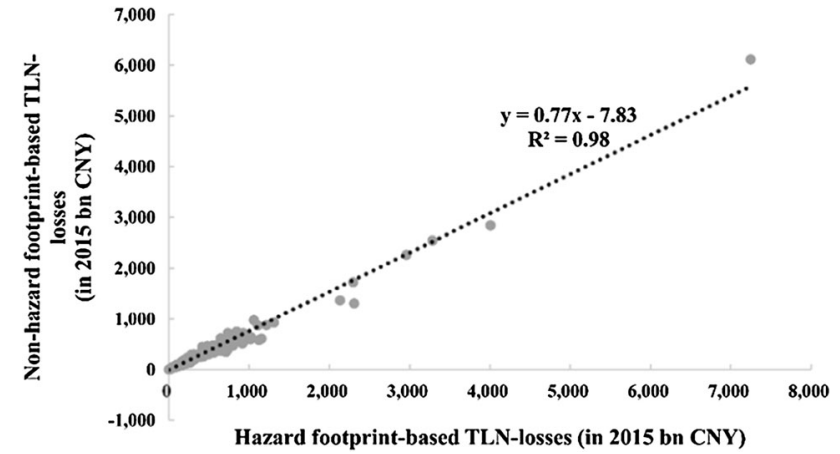

Fig. 10 Scatter plot showing the correlation between the loss normalization results from the hazard footprint-based and non-hazard footprint-based national-level (total) loss normalization (TLN) methods for the 217 influential tropical cyclones in China's mainland during 1983-2015

between the two methods. The hazard footprint-based normalization method has apparently made the estimation of exposures closer to reality, which is important for a close examination of the effects of socioeconomic factors on TC damage and losses. 


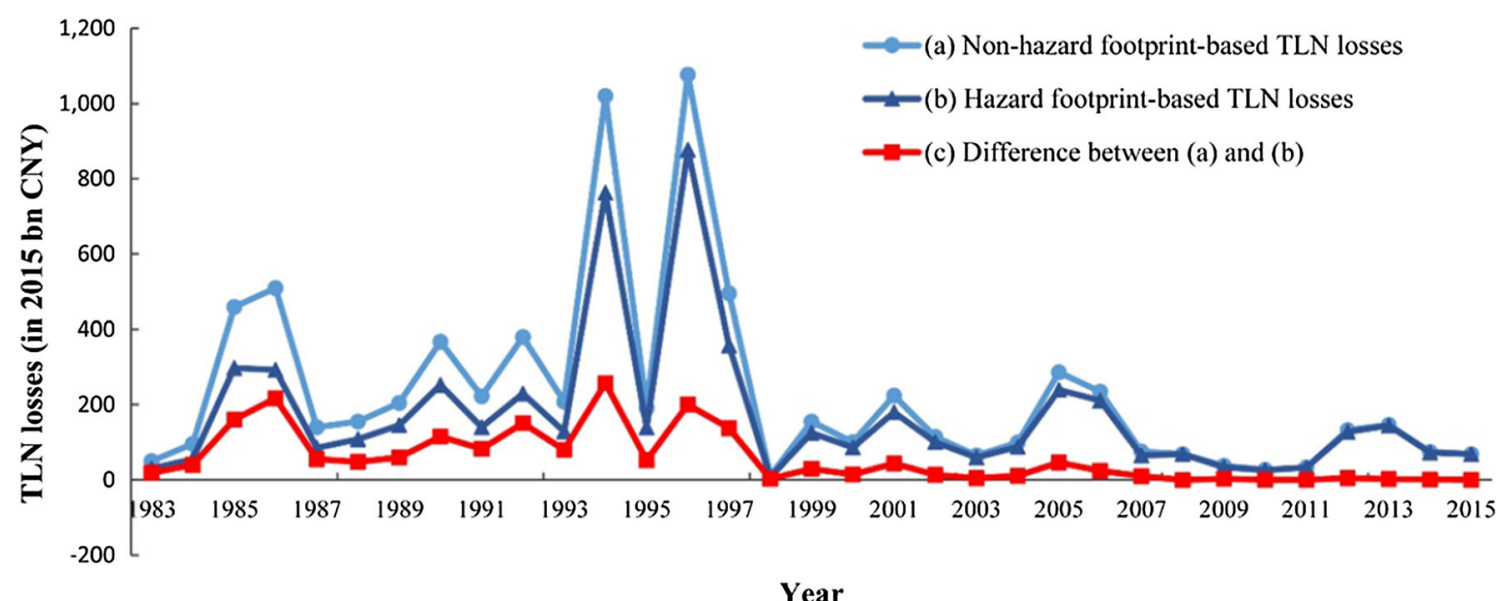

Fig. 11 Difference between annual total normalized losses from the hazard footprint-based and non-hazard footprint-based national-level (total) loss normalization (TLN) methods in China's mainland during 1983-2015

\section{Conclusion}

This study explored the hazard footprint-based loss normalization method of TCs in China's mainland over the 33 years from 1983 to 2015 . The hazard footprints of influential TCs were identified by considering the intensities of the induced rainfall and wind, and then the affected ratio of areas of each province for each event was calculated to obtain the affected population and GDP at a higher spatial resolution. To make full use of the available data, two kinds of normalization-provincial-level and nationallevel (total) loss normalization (PLN and TLN) were carried out, covering loss records over 1999-2015 and 1983-2015, respectively. Trends in inflation-adjusted losses and normalized losses were tested using both the linear regression method and the non-parametric Mann-Kendall method.

Losses were normalized using inflation ratio, population ratio, and wealth (GDP per capita) ratio in both provincialand national- level normalizations. The results of the PLNlosses show that TC risks concentrate in the provinces of Zhejiang, Guangdong, Fujian, Guangxi, and Hainan in terms of both inflation-adjusted losses and normalized losses. However, no significant linear or non-linear trend was found in either the inflation-adjusted losses or the PLN-losses. But the results of the TLN-losses show that there is an upward non-linear trend in inflation-adjusted losses but no trend in the TLN-losses.

Our study found that socioeconomic factors have contributed substantially to the increasing TCs' damages and losses, which is consistent with most of the previous studies (Zhang et al. 2009, 2011; Fischer et al. 2015). More attention should be paid to the high-risk coastal areas and the potential catastrophic damages caused by landfall TCs along with the rapid growth of population and wealth. By applying a hazard footprint-based loss normalization at both provincial and national levels, this study has improved the current methods of loss normalization for TCs in China and contributed to a better understanding of TC risks under the current socioeconomic conditions.

This study, nevertheless, has several limitations. Like many other studies, it assumed constant vulnerability over time in the loss normalization process, which may not be true in reality (Estrada et al. 2015). Although vulnerability is much more difficult to calibrate, more studies on the change of vulnerability and the associated effects on TC risks should be carried out in the future. Also, the assumption that losses are proportional to the population and wealth ignores the more complex interactions between these factors (Estrada et al. 2015). But a more robust model has not yet been established (Hallegatte 2015) and further research and discussion are needed.

Acknowledgements This study was supported by the National Basic Research Program of China (Grant No. 2015CB452806) and the National Natural Science Foundation of China (Grant No. 41701103). The authors would like to thank the editors and the anonymous reviewers for their constructive comments on the manuscript.

Open Access This article is distributed under the terms of the Creative Commons Attribution 4.0 International License (http://crea tivecommons.org/licenses/by/4.0/), which permits unrestricted use, distribution, and reproduction in any medium, provided you give appropriate credit to the original author(s) and the source, provide a link to the Creative Commons license, and indicate if changes were made.

\section{References}

Bouwer, L.M. 2011. Have disaster losses increased due to anthropogenic climate change? Bulletin of the American Meteorological Society 92(1): 39-46. 
CMA (China Meteorological Administration). 2000-2004. China's yearbooks of meteorology. Beijing: China Meteorological Press (in Chinese).

CMA (China Meteorological Administration). 2005-2016. China's yearbooks of meteorological disaster. Beijing: China Meteorological Press (in Chinese).

Crompton, R.P., S. Schmidt, L. Wu, R. Pielke Jr, R. Musulin, and E. Michel-Kerjan. 2010. Topic 4.5: economic impacts of tropical cyclones. In Proceedings of seventh international workshop on tropical cyclones, 15-20 November 2010, La Réunion, France, 4.5.1-4.5.23.

Eichner, J. 2013. Loss trends-How much would past events cost by today's standards? In Topics GEO 2012, ed. A. Wirtz, and A. Schuck, 56-59. München: Munich Re.

Eichner, J., P. Löw, and M. Steuer. 2016. Innovative new ways of analysing historical loss events. In Topics GEO 2015, ed. B. Brix, 62-66. München: Munich Re.

Estrada, F., W.J.W. Botzen, and R.S.J. Tol. 2015. Economic losses from US hurricanes consistent with an influence from climate change. Nature Geoscience 8(11): 880-884.

Fischer, T., B. Su, and S. Wen. 2015. Spatio-temporal analysis of economic losses from tropical cyclones in affected provinces of China for the last 30 years (1984-2013). Natural Hazards Review 16(4): Article 04015010.

Gemmer, M., Y.Z. Yin, Y. Luo, and T. Fischer. 2011. Tropical cyclones in China: County-based analysis of landfalls and economic losses in Fujian Province. Quaternary International 244(2): 169-177.

Haan, C.T. 1977. Statistical methods in hydrology. Ames: Iowa State University Press.

Hallegatte, S. 2015. Climate change: Unattributed hurricane damage. Nature Geoscience 8(11): 819-820.

Kendall, M. 1975. Rank correlation methods, 4th edn. London: Charles Griffin.

Lu, Y., W. Zhu, F. Ren, and X. Wang. 2016. Changes of tropical cyclone high winds and extreme winds during 1980-2014 over China. Climate Change Research 12(5): 413-421 (in Chinese).

Mann, H.B. 1945. Nonparametric tests against trend. Econometrica 13(3): 245-259.

NBSC (National Bureau of Statistics of China). 2016. China city statistical yearbook. Beijing: China Statistics Press (in Chinese).

NBSC (National Bureau of Statistics of China). 2015. 2015 statistical bulletin of national economic and social development. http://www. stats.gov.cn/tjsj/zxfb/201602/t20160229_1323991.html. Accessed 29 Mar 2018 (in Chinese).

NCC (National Climate Center). 2001. China's tropical cyclone disasters dataset (1949-1999). http://data.cma.cn/data/cdcdetail/
dataCode/DISA_TYP_DIS_CHN.html. Accessed 20 Mar 2018 (in Chinese).

Pattanayak, S., and D.N. Kumar. 2013. Review of trend detection methods and their application to detect temperature changes in India. Journal of Hydrology 476(1): 212-227.

Pielke Jr, R.A., and C.W. Landsea. 1998. Normalized hurricane damages in the United States: 1925-95. Weather and Forecasting 13(3): 621-631.

Pielke Jr, R.A., J. Gratz, C.W. Landsea, D. Collins, M.A. Saunders, and R. Musulin. 2008. Normalized hurricane damage in the United States: 1900-2005. Natural Hazards Review 9(1): 29-42.

Pielke Jr, R.A., J. Rubiera, C. Landsea, M.L. Fernández, and R. Klein. 2003. Hurricane vulnerability in Latin America and the Caribbean: Normalized damage and loss potentials. Natural Hazards Review 4(3): 101-114.

Raghavan, S., and S. Rajesh. 2003. Trends in tropical cyclone impact: A study in Andhra Pradesh, India. Bulletin of the American Meteorological Society 84(5): 635-644.

Ren, F., Y. Wang, X. Wang, and L. Weijing. 2007. Estimating tropical cyclone precipitation from station observations. Advances in Atmospheric Sciences 24(4): 700-711.

Sander, J., J.F. Eichner, E. Faust, and M. Steuer. 2013. Rising variability in thunderstorm-related U.S. losses as a reflection of changes in large-scale thunderstorm forcing. Weather, Climate and Society 5(4): 317-331.

Schmidt, S., C. Kemfert, and P. Höppe. 2009. Tropical cyclone losses in the USA and the impact of climate change-A trend analysis based on data from a new approach to adjusting storm losses. Environmental Impact Assessment Review 29(6): 359-369.

Swiss Re. 2016. Natural catastrophes and man-made disasters in 2015: Asia suffers substantial losses. https://reliefweb.int/sites/ reliefweb.int/files/resources/sigma1_2016_en.pdf. Accessed 9 May 2018.

Wang, Y., S. Wen, X. Li, F. Thomas, B. Su, R. Wang, and T. Jiang. 2016. Spatiotemporal distributions of influential tropical cyclones and associated economic losses in China in 1984-2015. Natural Hazards 84(3): 2009-2030.

Ying, M., W. Zhang, H. Yu, X. Lu, J. Feng, Y. Fan, Y. Zhu, and D. Chen. 2014. An overview of the China Meteorological Administration tropical cyclone database. Journal of Atmospheric and Oceanic Technology 31(2): 287-301.

Zhang, Q., Q. Liu, and L. Wu. 2009. Tropical cyclone damages in China 1983-2006. Bulletin of the American Meteorological Society 90(4): 489-495.

Zhang, J., L. Wu, and Q. Zhang. 2011. Tropical cyclone damages in China under the background of global warming. Journal of Tropical Meteorology 27(4): 442-454 (in Chinese). 